\title{
Collaboratively Developing Open Educational Resources for Engineering Educators in SlideWiki
}

\author{
https://doi.org/10.3991/ijep.v9i2.9959 \\ Maria Moundridou ( ${ }^{\varpi}$, Eleni Zalavra, Kyparisia Papanikolaou, Angeliki Tripiniotis \\ School of Pedagogical and Technological Education, Athens, Greece \\ mariameaspete.gr
}

\begin{abstract}
This paper reports on a study that was conducted to explore the potential of SlideWiki for collaborative content creation in a teacher education context. SlideWiki is a newly developed platform built on the Open Educational Resources (OER) ethos aiming to facilitate the collaboration around educational content. In this study, 134 students (pre-service engineering educators) used SlideWiki to collaboratively develop OERs in the form of WebQuests. The students' answers to a survey questionnaire were used to address their experience, while real interaction data from the SlideWiki platform were used to determine the students' participation in SlideWiki during the development of OERs both as individuals and in groups. The study yielded positive findings regarding students' perceptions of the potential of SlideWiki to serve as an effective tool for collaboratively developing OERs and of its usefulness and effectiveness for supporting communities of educators. Also, assuming their future role as educators, the students expressed their intention to utilize SlideWiki in their practice. However, a discrepancy was noticed between students' perceptions and their actual participation in SlideWiki (e.g. unequal distribution of workload among group members) that may be due to the students' lack of collaborative skills that need to be further cultivated.
\end{abstract}

Keywords-Collaborative content creation, wikis, open educational resources, engineering education, SlideWiki

\section{$1 \quad$ Introduction}

In this paper, we explore the potential of wikis for collaborative content creation in a teacher education context. In particular, we report on a study in which 134 students (pre-service teachers) working on the design of technology-enhanced learning activities, collaboratively developed WebQuests [1], using a specific wiki platform, SlideWiki (http://slidewiki.org) [2]. SlideWiki is a platform supporting the crowdsourced creation of richly structured learning content, facilitating collaborative authoring and allowing the elicitation and sharing of knowledge using presentations [3].

Wheeler, Yeomans \& Wheeler [4] consider that Wikis enable students to collaboratively generate, mix, edit and synthesise subject specific knowledge within a shared 
and openly accessible digital space. Considering that little technical ability is required to use wikis [5], this technology permits students to focus on collaboration and the exchange of information [6]. Although wikis include features that facilitate collaboration, it does not necessarily follow that their use will ensure or even encourage collaborative learning behaviour [7], as collaboration is not automatically a direct outcome of wiki technology [8]. Moreover, crowdsourcing as large-scale collaboration around educational content is currently supported only in a very limited way [2]. Applications like Google Docs or Prezi, support collaborative authoring of particular type of content, whilst applications like SlideShare, TeacherTube, or OpenStudy, are commonly used as educational social networks allowing the sharing of various types of content like slides, presentations, diagrams, assessment tests etc., which are mainly created individually.

However, collaborative content authoring is a challenge for the educational community as well as for the teacher education area. Especially WebQuests [1], are considered to provide an excellent organisational model for teacher education [9];[10]. Furthermore, the collaborative development of WebQuests is a promising way of enhancing the comprehension of inquiry-based learning and digital technologies, focusing on the synthesis of pedagogy, content and technology [9].

This paper extends work presented by the authors in [11]. The paper aims at addressing the potential of wikis as crowd-sourcing platforms supporting collaborative authoring of Open Educational Resources (OERs), through the evaluation of the newly developed SlideWiki platform being utilised in a constructivist teacher-training context. In the remainder of this paper, we first introduce the SlideWiki platform and its main features and functionalities. Then we describe the empirical study conducted in an undergraduate course on technology-enhanced learning for engineering educators who used SlideWiki to collaboratively develop OERs in the form of WebQuests. The collected data include students' answers to a survey questionnaire as well as real interaction data from the SlideWiki platform. The former are used to address how the students assess SlideWiki as an environment for collaboratively developing OERs, what are their perceptions of SlideWiki for supporting communities of educators and what are their intentions for utilizing it as future teachers. Interaction data come from the history feature of SlideWiki and they are used to determine students' participation in SlideWiki while developing OERs both as individuals and as groups. The conclusions drawn from the study's findings -discussed in the last section of the paper- are of value both for the area of teacher education and as for the development of wikis as crowd-sourcing platforms supporting collaborative authoring.

\section{$2 \quad$ SlideWiki}

SlideWiki (http://SlideWiki.org) is a platform aiming to facilitate the collaboration around educational content [2]. Focusing on educational content creation, the platform is grounded on reusable content authoring and large-scale community collaboration (or crowdsourcing) [12]. Inspired by the wiki paradigm, which since its inception in the early 2000s has become a ubiquitous pillar for enabling large-scale collaboration, 
Tarasowa, Khalili \& Auer [12] envisioned extending its unstructured, textual content. Aiming to support (semi-)structured content creation (e.g. presentations, questionnaires, diagrams, etc.) and the collaboration of large user communities around such content, they developed the CrowdLearn concept and applied it to SlideWiki. The CrowdLearn concept combines the wiki style for collaborative content authoring -in the form of presentation slides- with the requirements of the Sharable Content Object Reference Model (SCORM) for reusability [13].

For someone to use SlideWiki, a user account needs to be created, either by signing up or by using a Google or GitHub login. In SlideWiki, users can create slides, arrange them in presentations, and collaborate on them [2]. Actually, the term "deck" is adopted for a collection of slides that users can either create from scratch or import from PowerPoint or OpenDocument Presentation files. In decks, tags can be assigned and a commenting feature is available. Authoring the slides within a deck follows the familiar approach of editing a presentation. A horizontal toolbar including all the basic features for formatting a slide (e.g. defining fonts, arranging paragraphs in textboxes, etc.) is provided, along with a vertical toolbar with tools for embedding images, videos, tables, equations, and other content. Moreover, SlideWiki employs an inline HTML5 based WYSIWYG text editor so that users can see the slideshow output at the same time as they are authoring their slides [3].

SlideWiki allows users to collaborate through managing editing rights in a deck. The deck creator can authorize other users to edit the deck. SlideWiki supports versioning, forking/branching and merging for slides and decks, ensuring that every user's personal revisions of slides and decks are always preserved [2]. When a deck or a slide is forked (copied), information about its origin and its creator is displayed in the deck description. Consequentially, SlideWiki attributes three roles to users: a) 'origin' for the first user who created a deck, b) 'creator' for the user who forked a deck and c) 'contributor' for the user who has edit rights to the deck.

SlideWiki is built on the Open Educational Resources (OER) ethos and all content available in it, is licensed under the Creative Commons Attribution Share Alike license (CC-BY-SA) [2]. In this way, users can share, re-purpose and reuse content for their own purposes, meaning that they can revise, adapt and re-mix any slides and decks on SlideWiki.

Figure 1 shows a screenshot of a deck developed during our study. The sidebar on the left:

- Includes the deck name and the slide list, which follows the WebQuest model.

- In the centre (2), there is information regarding the deck, including the creator and the origin, since this deck originated from another deck that had been forked.

- On the right sidebar (3), one can see the creator as well as the contributors of the deck, along with an activity feed showing the interaction of users with this deck (editing, commenting, and forking).

- At the bottom (4), there are features such as tagging and commenting.

- At the bottom right (5), there is the trademark of the Creative Common License under which the deck is published. 


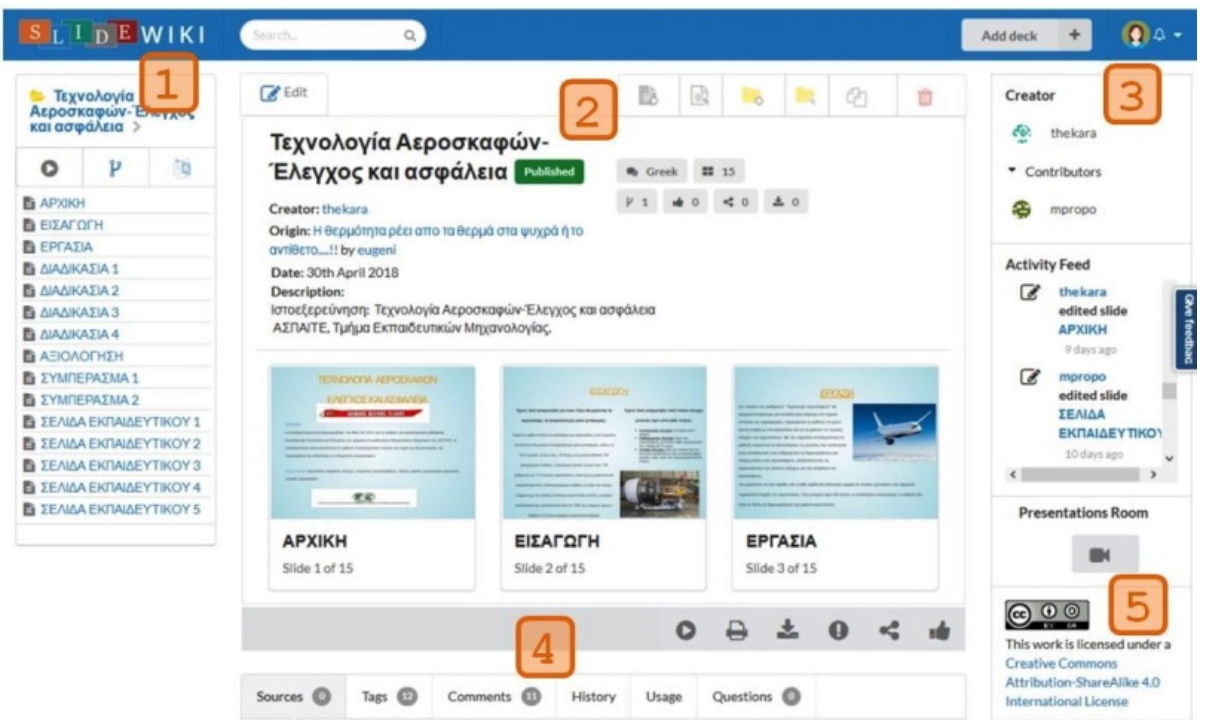

Fig. 1. A SlideWiki deck developed during our study (usernames altered)

\section{Empirical Study}

SlideWiki was used in an undergraduate course in order to evaluate in real educational settings some of its specific functionalities supporting community collaboration, authoring, reusing and re-purposing of educational content.

The research questions of the study are the following:

- RQ1: How do the students assess SlideWiki as an environment for collaboratively developing OERs?

- RQ2: What was the students' individual and group participation in SlideWiki during the development of OERs?

- RQ3: What are the students' perceptions of SlideWiki for supporting communities of educators and what are their intentions for utilizing it as future teachers?

\subsection{Methodology}

SlideWiki was used in the context of an Educational Technology undergraduate course offered in the School of Pedagogical and Technological Education (ASPETE), Athens, Greece, during the spring semester of the academic year 2017-18. The participants were 134 students of the departments of Civil Engineering Educators and Mechanical Engineering Educators. The research team included the two instructors of the course and two facilitators.

In this course, it is compulsory for students to carry out a learning design activity as their final project. Specifically, they are assigned to collaboratively develop a learning design according to a set of technological and pedagogical specifications. In 
particular, students are asked to use the WebQuest model of inquiry [1]; [9] and to integrate technologies, such as web 2.0 tools, into their learning designs.

In this study, the students' project was organised over a seven-week period as a blended learning activity as follows:

- $1^{\text {st }}$ week: Students were informed about the framework of the activity. They were introduced to the SlideWiki platform, created user accounts and got familiar with it.

- $2^{\text {nd }}$ week: Students were asked to explore exemplary OERs (WebQuests) which were already prepared and published as SlideWiki decks by the research team. They were also asked to comment on one exemplar WebQuest following specific evaluation criteria given by the research team.

- $3^{\text {rd }}$ week: Students were introduced to the final assignment of the course asking them to collaboratively develop a WebQuest as a deck in SlideWiki. They formed groups, mainly of two and in a few cases of three members, and organised their collaboration in SlideWiki by sharing a deck and defining its contributors.

- $4^{\text {th }}-5^{\text {th }}$ week: Students developed their WebQuests in SlideWiki.

- $6^{\text {th }}$ week: Peer review was organized. Each student commented on the SlideWiki Deck of another group about the appropriateness of technology and pedagogy integration in the design, following specific evaluation criteria given by the research team. The same criteria were used by the course instructors too, who also commented on the Decks where the WebQuests were published.

- $7^{\text {th }}$ week: Taking into account the reviews received by their peers and the instructor, each student group was allowed to revise and improve its WebQuest.

While students were working on their project they were also attending the course in a weekly basis. Therefore, they participated in 6 face-to-face lab sessions. The tutors were also available to support them in a forum set up for this purpose.

At this point, it is worth mentioning that the activity was structured by means of a framework for organising collaborative learning design activities, proposed by Zalavra and Papanikolaou [14]. This framework utilises Salmon's five-stage model [15];[16], a valuable curriculum-building tool for designing and implementing etivities based on e-learning tools. It restructures the context of Salmon's model from e-learning to blended learning and proposes how the stages should be implemented specifically for organizing a collaborative learning design activity in a wiki platform. This study also serves as an empirical study of this framework to be analysed in another paper.

At the end of the course, students completed a survey questionnaire assessing the students' learning design experience (evaluation questionnaire).

\subsection{Data collection and analysis}

Having in mind that research studies of educational wiki implementations are mostly perception-based [7] while the wiki data log is considered as inherently more 
reliable to explore collaborative writing activities [8], we use both students' perceptions and real interaction data from the SlideWiki platform.

The data collected consist of: (a) 125 survey questionnaires concerning the students' experience and perceptions, and (b) 67 OERs in the form of a WebQuest, as SlideWiki decks developed by 134 students, mostly working in groups of two.

The survey questionnaire comprised of 37 questions: 32 Likert-scaled ones (ranging from 1: strongly disagree to 5: strongly agree), 3 open-ended ones, and a multiple choice one, organised in four sections focusing on the following aspects:

- Section A: SlideWiki's usefulness and ease of use for developing OERs (Q1-Q11, Tables: 1, 2 and 3)

- Section B: SlideWiki facilitating collaboration among co-developers of OERs (Q12-Q23, Table 4)

- Section C: SlideWiki supporting communities of educators (Q24-Q32, Table 5)

- Section D: Utilizing SlideWiki as future teachers (Q33-Q37, Tables 6 and 7)

In this research we analysed the Sections A and B of the survey questionnaire in order to provide evidence about SlideWiki as an environment for collaboratively developing OERs (RQ1) based on the students' perceptions. Moreover, we analysed the students' responses to the sections $\mathrm{C}$ and $\mathrm{D}$ of the survey questionnaire in order to provide evidence about the students' perceptions of SlideWiki for supporting communities of educators, as well as their intentions for utilizing it as future teachers themselves (RQ3).

To specify the students' behaviour in SlideWiki during the development of their OERs both individually and in groups (RQ2), we considered how much did each student contribute to group work and when did students choose to work for the development of their OERs. The individual contribution to group work and the group work timeline were determined using the history feature available in each slide of a deck and analysing the number of edits that each group member did in the group's Deck as well as the time that these edits occurred.

\subsection{Findings}

- RQ1: How do the students assess SlideWiki as an environment for collaboratively developing OERs? SlideWiki was assessed by students along two dimensions:

- Its usefulness and ease of use for developing OERs

- Its potentiality in facilitating collaboration among co-developers

SlideWiki's usefulness and ease of use for developing OERs: Table 1 summarises the students' responses in statements that address how they perceive SlideWiki's usefulness and ease of use when developing an OER. In line with the results of previous research [17], where pre-service engineering educators found wikis to be easy to use platforms for content delivery, $80 \%$ of students agreed or strongly agreed that the platform was easy to access and use (Q1) and $69 \%$ used it without any assistance (Q2). 79\% of students appreciated the ability to access their work anytime from any- 
where $(\mathrm{Q} 3)$ and $61 \%$ stated that this ability motivated them to work on their assignment (Q4).

Table 1. Distribution of students' responses in statements Q1 to Q9 of Section A

\begin{tabular}{|l|c|c|c|c|c|}
\hline \multicolumn{1}{|c|}{ Statement } & $\mathbf{1}$ & $\mathbf{2}$ & $\mathbf{3}$ & $\mathbf{4}$ & $\mathbf{5}$ \\
\hline Q1. I could easily access and use SlideWiki. & $\begin{array}{c}3 \\
(2 \%)\end{array}$ & $\begin{array}{c}7 \\
(6 \%)\end{array}$ & $\begin{array}{c}15 \\
(12 \%)\end{array}$ & $\begin{array}{c}76 \\
(61 \%)\end{array}$ & $\begin{array}{c}24 \\
(19 \%)\end{array}$ \\
\hline $\begin{array}{l}\text { Q2. I used SlideWiki for my assignment without } \\
\text { needing any assistance. }\end{array}$ & $\begin{array}{c}0 \\
(0 \%)\end{array}$ & $\begin{array}{c}11 \\
(9 \%)\end{array}$ & $\begin{array}{c}28 \\
(22 \%)\end{array}$ & $\begin{array}{c}72 \\
(58 \%)\end{array}$ & $\begin{array}{c}12 \\
(11 \%)\end{array}$ \\
\hline $\begin{array}{l}\text { Q3. I appreciate that SlideWiki allowed me to } \\
\text { access my work anytime, from anywhere. }\end{array}$ & $\begin{array}{c}3 \\
(2 \%)\end{array}$ & $\begin{array}{c}8 \\
(6 \%)\end{array}$ & $\begin{array}{c}16 \\
(13 \%)\end{array}$ & $\begin{array}{c}66 \\
(53 \%)\end{array}$ & $\begin{array}{c}32 \\
(26 \%)\end{array}$ \\
\hline $\begin{array}{l}\text { Q4. The ability to access my work from anywhere, } \\
\text { at any time, has motivated me to work my task. }\end{array}$ & $3(2 \%)$ & $\begin{array}{c}9 \\
(7 \%)\end{array}$ & $\begin{array}{c}36 \\
(29 \%)\end{array}$ & $\begin{array}{c}53 \\
(42 \%)\end{array}$ & $\begin{array}{c}24 \\
(19 \%)\end{array}$ \\
\hline $\begin{array}{l}\text { Q5. Structuring the content as Slide Deck was } \\
\text { practical and intuitive. }\end{array}$ & $\begin{array}{c}4 \\
(3 \%)\end{array}$ & $\begin{array}{c}17 \\
(14 \%)\end{array}$ & $\begin{array}{c}18 \\
(14 \%)\end{array}$ & $\begin{array}{c}61 \\
(49 \%)\end{array}$ & $\begin{array}{c}25 \\
(20 \%)\end{array}$ \\
\hline $\begin{array}{l}\text { Q6. I enjoyed SlideWiki's feature for easily inte- } \\
\text { grating images, videos and Web 2.0 objects into } \\
\text { slides. }\end{array}$ & $2(2 \%)$ & $\begin{array}{c}3 \\
(2 \%)\end{array}$ & $\begin{array}{c}10 \\
(8 \%)\end{array}$ & $\begin{array}{c}62 \\
(50 \%)\end{array}$ & $\begin{array}{c}48 \\
(38 \%)\end{array}$ \\
\hline $\begin{array}{l}\text { Q7. SlideWiki's feature for authorizing contribu- } \\
\text { tors in Slide Decks and providing a history of their } \\
\text { actions prompted me to participate actively. }\end{array}$ & $\begin{array}{c}2 \\
(2 \%)\end{array}$ & $\begin{array}{c}3 \\
(2 \%)\end{array}$ & $\begin{array}{c}34 \\
(27 \%)\end{array}$ & $\begin{array}{c}67 \\
(54 \%)\end{array}$ & $\begin{array}{c}19 \\
(15 \%)\end{array}$ \\
\hline $\begin{array}{l}\text { Q8. I would like SlideWiki's history feature to } \\
\text { provide a review of the actions carried out within } \\
\text { each slide and the users who performed them. }\end{array}$ & $\begin{array}{c}1 \\
(1 \%)\end{array}$ & $\begin{array}{c}6 \\
(5 \%)\end{array}$ & $\begin{array}{c}32 \\
(26 \%)\end{array}$ & $\begin{array}{c}58 \\
(46 \%)\end{array}$ & $\begin{array}{c}28 \\
(22 \%)\end{array}$ \\
\hline $\begin{array}{l}\text { Q9. I would like the SlideWiki's history feature to } \\
\text { support reverting to previous versions of slides. }\end{array}$ & $\begin{array}{c}0 \\
(0 \%)\end{array}$ & $\begin{array}{c}3 \\
(5 \%)\end{array}$ & $\begin{array}{c}20 \\
(16 \%)\end{array}$ & $\begin{array}{c}63 \\
(50 \%)\end{array}$ & $\begin{array}{c}39 \\
(31 \%)\end{array}$ \\
\hline
\end{tabular}

The most popular ( $88 \%$ of students) feature of SlideWiki was the easy integration of images, videos, and Web 2.0 objects into slides (Q6). 69\% of students felt that they were prompted to participate actively in their assignment due to SlideWiki's feature for authorizing contributors in Slide Decks and providing a history of their actions (Q7). However, $68 \%$ of students would also like the history feature to provide a review of the actions carried out within the content of each slide and the users who made them (Q8), and 81\% would like to be able to revert to previous versions of slides (Q9). Concerning the structuring of content as Slide Decks, while 69\% of students find it to be practical and intuitive, a not negligible 17\% disagree (Q5).

Table 2. Students' responses to the open-ended question (Q10) of Section A

\begin{tabular}{|l|c|}
\hline \multicolumn{2}{|c|}{ Q10. Which features of SlideWiki do you consider useful for your assignment? } \\
\hline \multicolumn{1}{|c|}{ Category of responses } & Frequency \\
\hline Slide Authoring: Integrating images, videos and tables & $57(46 \%)$ \\
\hline Slide Authoring: Adding Hyperlinks & $16(13 \%)$ \\
\hline Online access provided easy access & $37(30 \%)$ \\
\hline Familiar content structure (PowerPoint alike) & $31(25 \%)$ \\
\hline Sharing a deck with my peers and working synchronously & $26(21 \%)$ \\
\hline Being able to see exemplar as well as other groups' WebQuests & $10(8 \%)$ \\
\hline When my deck/slide is copied, my copyrights are preserved & $4(3 \%)$ \\
\hline
\end{tabular}


Students were also asked to name the most useful features of SlideWiki for their assignment (Table 2), as well as the features that interfered with their work (Table 3).

Integrating images, videos, and tables into slides was considered useful by nearly half of the students (46\%). 30\% of the students considered it useful that their work was performed and stored online, enabling them to easily access it from anywhere, at any time. One out of four students favoured that content in SlideWiki is structured in the form of slides, which is familiar to them from presentation software like MSPowerPoint. Sharing a Slide Deck with peers and working synchronously on it, was considered useful by $21 \%$ of students. Fewer students considered other features of SlideWiki useful, namely: adding hyperlinks to slides (13\%), being able to see others' Decks (8\%), and preserving the copyrights when a Deck is copied (3\%).

Table 3. Students' responses to the open ended question (Q11) of Section A

\begin{tabular}{|l|c|}
\hline \multicolumn{1}{|c|}{ Q11. Which features of SlideWiki do you consider that interfered with your assignment? } \\
\hline \multicolumn{1}{|c|}{ Category of responses } & Frequency \\
\hline Slide Authoring: handling content boxes. & $54(43 \%)$ \\
\hline Slide Authoring: not enough features for text and/or image formatting & $13(10 \%)$ \\
\hline Slide Authoring: formatting a table & $11(9 \%)$ \\
\hline Slide Authoring: toolbar for formatting text occasionally not visible & $4(3 \%)$ \\
\hline Slide Authoring: not being able to define my own background style & $2(2 \%)$ \\
\hline Platform not responding e.g. when saving a slide & $27(22 \%)$ \\
\hline Platform working slowly & $16(13 \%)$ \\
\hline Overall impression that platform is not easy to use & $10(8 \%)$ \\
\hline Not being able to collaborate synchronously on the same slide & $3(2 \%)$ \\
\hline No support for communication among contributors & $2(2 \%)$ \\
\hline Not being able to attach material (e.g. upload a pdf file) & $2(2 \%)$ \\
\hline None & $15(12 \%)$ \\
\hline
\end{tabular}

On the other hand, there were features of SlideWiki that interfered with the students' work. In fact, as shown in Table 3, the students' responses reveal that what interfered with their work was either a platform's malfunction or a missing feature. Malfunctions include: handling content boxes (43\%), formatting tables $(9 \%)$, platform not responding $(22 \%)$ or responding slowly $(13 \%)$. Missing features include: not enough features for text and/or image formatting (10\%), not being able to collaborate synchronously on the same slide $(2 \%)$, no support for communication among contributors $(2 \%)$, not being able to attach material -e.g. upload a pdf file $(2 \%)$. It should also be noted that $8 \%$ of students said that the platform was overall not easy to use. On the other hand, $12 \%$ did not view any feature of SlideWiki as interfering with their work.

SlideWiki facilitating collaboration among co-developers of OERs: The students' responses in statements addressing their perceptions about SlideWiki's potentiality in facilitating their collaboration while they were developing their WebQuests (Table 4) indicate that the platform performed well at that indeed. In particular, $89 \%$ of the students appreciated the fact that SlideWiki allowed them to share their work with their group (Q12) and 81\% stated that being able to author the assignment at their convenience, facilitated the collaboration (Q13). Although it is acknowledged that students consider face-to-face collaboration to be more effective than online collabo- 
ration in a Wiki environment [18];[5], it is quite promising that $44 \%$ of the particular students -even if they have only basic digital skills- considered it otherwise (Q14).

About two out of three students agreed or strongly agreed that the platform helped them save time (Q15) and facilitated the collaboration in their group (Q16). Moreover, $86 \%$ of students enjoyed collaborating within their group on a shared SlideWiki Deck (Q20) and 85\% thought that in this way all group members might equally contribute to the assigned task (Q21). SlideWiki also did fairly well at enhancing the sense of community in the class through collaboration (65\%, Q17), at motivating students to improve their work due to its availability as an OER to all SlideWiki users (72\%, Q22), and at stimulating the students' creativity by enabling them to review fellow groups' WebQuests while developing their own (74\%, Q23). A quite unexpected but welcome finding was that 9 out of 10 students felt comfortable commenting on SlideWiki Decks developed by others (Q19). This may indicate that assigning to students to comment following specific guidelines can possibly be a solution to students' hesitation and unwillingness to comment in the Wiki environment as reported by previous studies [18] [7][4]. Finally, 70\% of students suggested that collaboration could be further facilitated if SlideWiki provided a forum for communication among group members (Q18).

Table 4. Distribution of the students' responses in statements Q12 to Q23 of Section B

\begin{tabular}{|c|c|c|c|c|c|}
\hline Statement & 1 & 2 & 3 & 4 & 5 \\
\hline $\begin{array}{l}\text { Q12. I appreciated that SlideWiki allowed me to share } \\
\text { my work with the other group members. }\end{array}$ & $\begin{array}{c}2 \\
(2 \%) \\
\end{array}$ & $\begin{array}{c}0 \\
(0 \%) \\
\end{array}$ & $\begin{array}{c}12 \\
(10 \%)\end{array}$ & $\begin{array}{c}71 \\
(57 \%) \\
\end{array}$ & $\begin{array}{c}40 \\
(32 \%)\end{array}$ \\
\hline $\begin{array}{l}\text { Q13. Being able to collaboratively author my assign- } \\
\text { ment, at my convenience, facilitated our collaboration. }\end{array}$ & $\begin{array}{c}1 \\
(2 \%) \\
\end{array}$ & $\begin{array}{c}2 \\
(2 \%) \\
\end{array}$ & $\begin{array}{c}21 \\
(17 \%) \\
\end{array}$ & $\begin{array}{c}70 \\
(56 \%) \\
\end{array}$ & $\begin{array}{c}31 \\
(25 \%)\end{array}$ \\
\hline $\begin{array}{l}\text { Q14. I consider collaboration at SlideWiki more effec- } \\
\text { tive than face-to-face collaboration. }\end{array}$ & $\begin{array}{c}7 \\
(6 \%) \\
\end{array}$ & $\begin{array}{c}18 \\
(14 \%) \\
\end{array}$ & $\begin{array}{c}44 \\
(35 \%) \\
\end{array}$ & $\begin{array}{c}38 \\
(30 \%) \\
\end{array}$ & $\begin{array}{c}18 \\
(14 \%) \\
\end{array}$ \\
\hline $\begin{array}{l}\text { Q15. SlideWiki helped me save time while collaborating } \\
\text { within my group. }\end{array}$ & $\begin{array}{c}3 \\
(2 \%) \\
\end{array}$ & $\begin{array}{c}12 \\
(10 \%) \\
\end{array}$ & $\begin{array}{c}25 \\
(20 \%) \\
\end{array}$ & $\begin{array}{c}60 \\
(48 \%) \\
\end{array}$ & $\begin{array}{c}25 \\
(20 \%) \\
\end{array}$ \\
\hline $\begin{array}{l}\text { Q16. SlideWiki facilitated the collaboration of my } \\
\text { group. }\end{array}$ & $\begin{array}{c}5 \\
(4 \%) \\
\end{array}$ & $\begin{array}{c}5 \\
(4 \%) \\
\end{array}$ & $\begin{array}{c}27 \\
(22 \%) \\
\end{array}$ & $\begin{array}{c}61 \\
(49 \%) \\
\end{array}$ & $\begin{array}{c}27 \\
(22 \%) \\
\end{array}$ \\
\hline $\begin{array}{l}\text { Q17. Collaborating in SlideWiki has enhanced the sense } \\
\text { of community in my class. }\end{array}$ & $\begin{array}{c}3 \\
(2 \%) \\
\end{array}$ & $\begin{array}{c}13 \\
(10 \%) \\
\end{array}$ & $\begin{array}{c}28 \\
(22 \%) \\
\end{array}$ & $\begin{array}{c}60 \\
(48 \%) \\
\end{array}$ & $\begin{array}{c}21 \\
(17 \%) \\
\end{array}$ \\
\hline $\begin{array}{l}\text { Q18. The collaboration could be further facilitated if } \\
\text { SlideWiki provided a forum for communication among } \\
\text { group members. }\end{array}$ & $\begin{array}{c}2 \\
(2 \%)\end{array}$ & $\begin{array}{c}7 \\
(6 \%)\end{array}$ & $\begin{array}{c}28 \\
(22 \%)\end{array}$ & $\begin{array}{c}60 \\
(48 \%)\end{array}$ & $\begin{array}{c}28 \\
(22 \%)\end{array}$ \\
\hline $\begin{array}{l}\text { Q19. I was comfortable commenting in SlideWiki Decks } \\
\text { developed by others. }\end{array}$ & $\begin{array}{c}2 \\
(2 \%)\end{array}$ & $\begin{array}{c}5 \\
(4 \%) \\
\end{array}$ & $\begin{array}{c}22 \\
(18 \%) \\
\end{array}$ & $\begin{array}{c}76 \\
(61 \%) \\
\end{array}$ & $\begin{array}{c}36 \\
(29 \%) \\
\end{array}$ \\
\hline $\begin{array}{l}\text { Q20. I enjoyed collaborating within my group in a } \\
\text { shared SlideWiki Deck. }\end{array}$ & $\begin{array}{c}0 \\
(0 \%) \\
\end{array}$ & $\begin{array}{c}4 \\
(3 \%) \\
\end{array}$ & $\begin{array}{c}14 \\
(11 \%) \\
\end{array}$ & $\begin{array}{c}77 \\
(61 \%) \\
\end{array}$ & $\begin{array}{c}31 \\
(25 \%) \\
\end{array}$ \\
\hline $\begin{array}{l}\text { Q21. Collaborating in a shared SlideWiki Deck allowed } \\
\text { my group's members to equally contribute to our task. }\end{array}$ & $\begin{array}{c}1 \\
(1 \%) \\
\end{array}$ & $\begin{array}{c}3 \\
(2 \%) \\
\end{array}$ & $\begin{array}{c}15 \\
(12 \%) \\
\end{array}$ & $\begin{array}{c}63 \\
(62 \%) \\
\end{array}$ & $\begin{array}{c}29 \\
(23 \%) \\
\end{array}$ \\
\hline $\begin{array}{l}\text { Q23. Developing a WebQuest in SlideWiki as an OER } \\
\text { available to all SlideWiki users motivated me to improve } \\
\text { it. }\end{array}$ & $\begin{array}{c}0 \\
(0 \%)\end{array}$ & $\begin{array}{c}3 \\
(2 \%)\end{array}$ & $\begin{array}{c}31 \\
(25 \%)\end{array}$ & $\begin{array}{c}61 \\
(50 \%)\end{array}$ & $\begin{array}{c}28 \\
(22 \%)\end{array}$ \\
\hline $\begin{array}{l}\text { Q12. Being able to review fellow groups' WebQuests } \\
\text { while developing mine stimulated my own creativity. }\end{array}$ & $\begin{array}{c}0 \\
(0 \%) \\
\end{array}$ & $\begin{array}{c}6 \\
(5 \%) \\
\end{array}$ & $\begin{array}{c}27 \\
(22 \%)\end{array}$ & $\begin{array}{c}4 \\
(49 \%) \\
\end{array}$ & $\begin{array}{c}31 \\
(25 \%) \\
\end{array}$ \\
\hline
\end{tabular}


RQ2: What was the students' individual and group participation in SlideWiki during the development of OERs? In order to specify the students' participation in SlideWiki during the development of their OERs, both as individuals and in groups, we considered:

- How much each student contributed to group work, in terms of the number of editing actions performed in their group's OER

- When the groups chose to work for the development of their OERs, in terms of the number of groups that performed editing actions per day during the seven-week period of the project.

Contribution to group work: Figures 2 and 3 show the distribution of editing actions among group members, for each group of students of the departments of Mechanical Engineering Educators and Civil Engineering Educators, respectively. In order to determine these distributions, we used the history log of each slide included in a group's slide deck to count the number of each member's editing actions, as well as the total number of editing actions performed by all members on all slides of the deck.

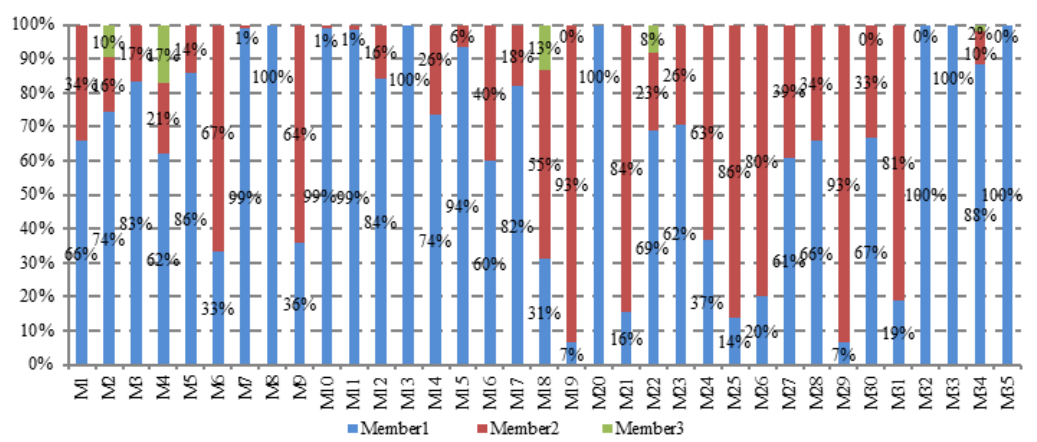

Fig. 2. Distribution of editing actions among group members for each group of students of the Department of Mechanical Engineering Educators

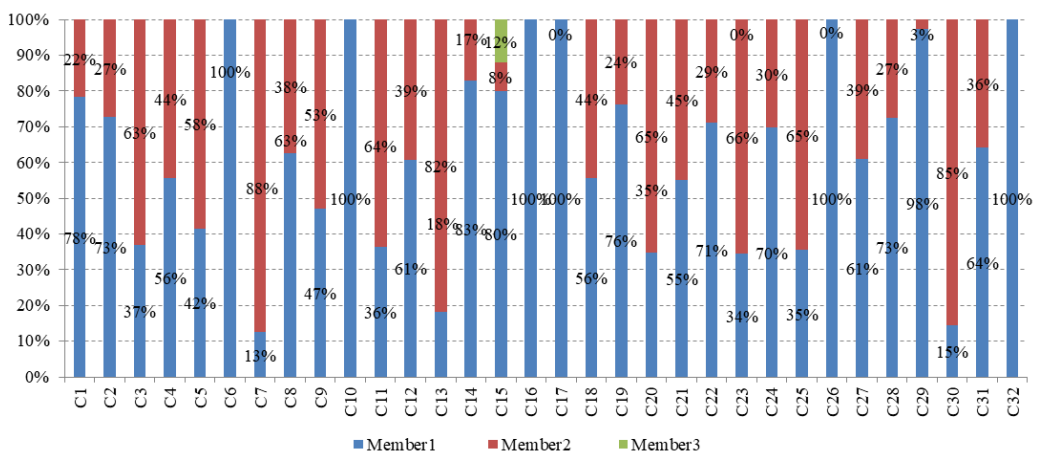

Fig. 3. Distribution of editing actions among group members for each group of students of the Department of Civil Engineering Educators 
Findings in Figures 2 and 3 reveal that the workload in groups of two (2) members was more equally distributed than in groups of three (3) members which confirm Goh's [19] suggestion to organize students in small groups in order to encourage interaction and engagement among them. Actually it was observed that in 6 out of 10 (60\%) groups of 3 members, either one member did not contribute at all (M19, M30, $\mathrm{M} 19, \mathrm{C} 22$ ) or made a minimal contribution by performing less than $10 \%$ of the editing actions (M22, M34, C15). On the other hand, it was observed that only in 10 out of $49(20 \%)$ groups of 2 members either one member did not contribute at all (M32, M35, C17, C26) or only minimally contributed by performing less than $10 \%$ of the editing actions (M7, M10, M11, M15, M29, C29).

Another finding from Figures 2 and 3 concerns the phenomenon of one member dominating the group work [20] [21]. Indeed, in more than half of groups consisting of two (2) or three (3) members (32 out of 59), one student alone did most of the work and dominated the group by contributing more than $70 \%$ of the editing actions (M2, M3, M5, M7, M10. M11, M12, M14, M15, M17, M19, M21, M25, M26, M29, M31, M34, M35, C1, C2, C7, C13, C14, C15, C17, C19, C22, C24, C26, C28, C29, C30).

At this point, we should mention that especially during the first three face-to-face lab sessions, most groups, although verbally collaborating, were working in SlideWiki using one of the user accounts. This behaviour seemed to have been gradually changing throughout the next lab sessions. Thus, the unbalanced work distribution and the 'one member dominating the group work' behaviour could either be attributed to the lack of collaborative authoring skills or to the phenomenon of social loafing [22].

Last, the fact that 8 out of 136 students $(6 \%)$ refused to collaborate in the first place and insisted on working on their own by forming one-member groups (M8, M13, M20, M33, C6, C10, C16, C32) can be attributed either to lacking social skills or to the predominant behaviourist learning paradigm [23].

The group work timeline: Figure 4 shows the timeline of the group work in the form of a line chart with two lines depicting the days when the groups of students from both departments (Dpt. of Mechanical Engineering Educators and Dpt. of Civil Engineering Educators) chose to work for the development of their OERs. The slides' history logs were once again used to count the number of groups that performed any editing action each day during the seven-week period of the project. The first peak in both series corresponds to the face-to-face lab session, when students were assigned the task of collaboratively developing an OER using the WebQuest model in SlideWiki. On that day, students formed groups, created and shared a Slide deck and started to collaborate.

The other peaks observed, also correspond to the days when students participated in face-to-face lab sessions according to the project schedule. A deeper look at the history logs of the slides authored on the particular days shows that the students authored their WebQuests both during the lab session and shortly after it on the same day. From this, it can be assumed that the face-to-face lab sessions included in the blended learning structure of the project triggered the students' collaboration by allowing them to organize their group work and overcome the lack of face-to-face contact constraining their collaboration [6]. 


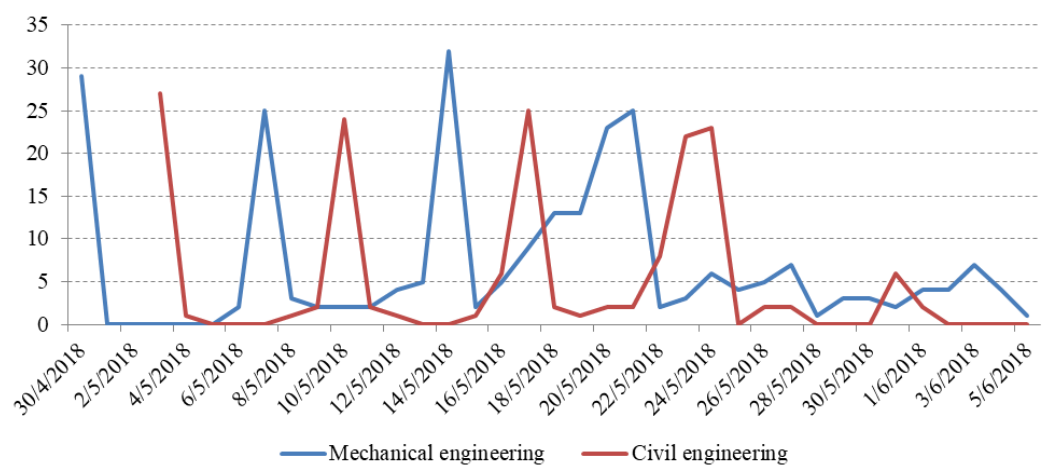

Fig. 4. The timeline depicting the days when the student groups worked on SlideWiki

The $4^{\text {th }}$ peak for both departments corresponds to the day that they had to have their WebQuest ready for the peer assessment activity and it is obvious that they worked more intensively just before this deadline. This observation confirms the students' tendency to postpone their work just before the deadline of their assignment [8] [7]; [20].

The lower number of editing actions observed in the chart during the last days correspond to the last period of the project, when groups, taking into account the reviews received by their peers and the instructor, were allowed to revise and improve their OERs (optional task). A possible explanation for the low level of their involvement is that the students tend to be more concerned with passing the course, doing as little work as possible, rather than learning collaboratively [8].

RQ3: What are the students' perceptions of SlideWiki for supporting communities of educators and what are their intentions for utilizing SlideWiki as future teachers? The students also assessed SlideWiki as for its usefulness for the educators, by expressing:

- Their perceptions of SlideWiki for supporting communities of educators

- Their intentions to utilize it in the future as teachers themselves.

SlideWiki supporting communities of educators: The students' perceptions concerning SlideWiki's support for communities of educators were addressed through their experience of utilizing the platform while developing their WebQuests and are presented in Table 5. 
Table 5. Distribution of the students' responses in statements Q24 to Q32 of Section C

\begin{tabular}{|c|c|c|c|c|c|}
\hline Statement & 1 & 2 & 3 & 4 & 5 \\
\hline $\begin{array}{l}\text { Q24. I can easily search for educational re- } \\
\text { sources available in SlideWiki. }\end{array}$ & $\begin{array}{c}2 \\
(2 \%) \\
\end{array}$ & $\begin{array}{c}7 \\
(6 \%) \\
\end{array}$ & $\begin{array}{c}20 \\
(16 \%) \\
\end{array}$ & $\begin{array}{c}70 \\
(56 \%) \\
\end{array}$ & $\begin{array}{c}26 \\
(21 \%) \\
\end{array}$ \\
\hline $\begin{array}{l}\text { Q25. I can easily locate the educational re- } \\
\text { sources I need in SlideWiki. }\end{array}$ & $\begin{array}{c}1 \\
(1 \%) \\
\end{array}$ & $\begin{array}{c}5 \\
(4 \%) \\
\end{array}$ & $\begin{array}{c}31 \\
(25 \%) \\
\end{array}$ & $\begin{array}{c}66 \\
(53 \%) \\
\end{array}$ & $\begin{array}{c}22 \\
(18 \%) \\
\end{array}$ \\
\hline $\begin{array}{l}\text { Q26. I consider it important that SlideWiki } \\
\text { provides access to OERs published under } \\
\text { Open Creative Commons license. }\end{array}$ & $\begin{array}{c}0 \\
(0 \%)\end{array}$ & $\begin{array}{c}3 \\
(2 \%)\end{array}$ & $\begin{array}{c}20 \\
(16 \%)\end{array}$ & $\begin{array}{c}77 \\
(62 \%)\end{array}$ & $\begin{array}{c}25 \\
(20 \%)\end{array}$ \\
\hline $\begin{array}{l}\text { Q27. I consider it important that SlideWiki } \\
\text { supports creating and publishing educational } \\
\text { resources under Open Creative Commons } \\
\text { license thus retaining the creator's copyright. }\end{array}$ & $\begin{array}{c}0 \\
(0 \%)\end{array}$ & $\begin{array}{c}5 \\
(4 \%)\end{array}$ & $\begin{array}{c}18 \\
(14 \%)\end{array}$ & $\begin{array}{c}78 \\
(62 \%)\end{array}$ & $\begin{array}{c}24 \\
(19 \%)\end{array}$ \\
\hline $\begin{array}{l}\text { Q28. I consider it important that SlideWiki } \\
\text { supports copying and reusing educational } \\
\text { resources under the CC-BY-SA } 4.0 \text { license, } \\
\text { thus allowing efficient collaboration. }\end{array}$ & $\begin{array}{c}0 \\
(0 \%)\end{array}$ & $\begin{array}{c}7 \\
(6 \%)\end{array}$ & $\begin{array}{c}18 \\
(14 \%)\end{array}$ & $\begin{array}{c}72 \\
(58 \%)\end{array}$ & $\begin{array}{c}28 \\
(22 \%)\end{array}$ \\
\hline $\begin{array}{l}\text { Q29. I consider it important that SlideWiki } \\
\text { supports developing a learning design in the } \\
\text { form of a WebQuest as slides in a deck. }\end{array}$ & $\begin{array}{c}0 \\
(0 \%)\end{array}$ & $\begin{array}{c}6 \\
(5 \%)\end{array}$ & $\begin{array}{c}26 \\
(21 \%)\end{array}$ & $\begin{array}{c}68 \\
(54 \%)\end{array}$ & $\begin{array}{c}25 \\
(20 \%)\end{array}$ \\
\hline $\begin{array}{l}\text { Q30. The exemplar WebQuests available in } \\
\text { the SlideWiki platform helped me develop my } \\
\text { group's WebQuest. }\end{array}$ & $\begin{array}{c}2 \\
(2 \%)\end{array}$ & $\begin{array}{c}4 \\
(3 \%)\end{array}$ & $\begin{array}{c}25 \\
(20 \%)\end{array}$ & $\begin{array}{c}70 \\
(56 \%)\end{array}$ & $\begin{array}{c}24 \\
(19 \%)\end{array}$ \\
\hline $\begin{array}{l}\text { Q31. Collaborating with my fellow students / } \\
\text { groupmates and co-authoring our WebQuest } \\
\text { has enhanced my own knowledge in learning } \\
\text { design / developing a WebQuest. }\end{array}$ & $\begin{array}{c}1 \\
(1 \%)\end{array}$ & $\begin{array}{c}8 \\
(6 \%)\end{array}$ & $\begin{array}{c}24 \\
(19 \%)\end{array}$ & $\begin{array}{c}69 \\
(55 \%)\end{array}$ & $\begin{array}{c}23 \\
(18 \%)\end{array}$ \\
\hline $\begin{array}{l}\text { Q32. I believe that SlideWiki has met the } \\
\text { requirement to serve as a platform for the } \\
\text { collaborative development of a WebQuest. }\end{array}$ & $\begin{array}{c}7 \\
(6 \%)\end{array}$ & $\begin{array}{c}8 \\
(6 \%)\end{array}$ & $\begin{array}{c}19 \\
(15 \%)\end{array}$ & $\begin{array}{c}67 \\
(54 \%)\end{array}$ & $\begin{array}{c}24 \\
(19 \%)\end{array}$ \\
\hline
\end{tabular}

The majority of the students stated that they could easily search for educational resources available in SlideWiki (77\%, Q24) and easily locate the ones they need (71\%, Q25). The fact that SlideWiki publishes content under the Open Creative Commons license was considered important by 8 out of 10 students (Q26-Q28).

Concerning the development of WebQuests, 73\% of the students agreed or strongly agreed that SlideWiki has met the requirement to serve as a platform for the collaborative development of a WebQuest (Q32). In particular, 74\% considered it important that SlideWiki supports developing a learning design in the form of a WebQuest as slides in a deck (Q29); 75\% stated that exemplar WebQuests available in the SlideWiki platform helped them develop their own WebQuest (Q30); and 73\% of the students said that their knowledge of learning design has been enhanced through the collaboration with peers and the co-authoring of WebQuests (Q31).

The students' intentions for utilizing SlideWiki as future teachers: Table 6 summarises the students' responses in statements that address their perceptions of SlideWiki's usefulness when they consider using it in the future. Assuming their future role as teachers, $50 \%$ stated that they intend to utilize the WebQuests their fellow students have developed at SlideWiki (Q33), 59\% would use SlideWiki to develop educational resources (Q34), and 58\% would choose to assign their students to use it (Q35). This positive attitude is in line with previous research reporting that pre- 
service teachers responded positively to the perspective of integrating a Wiki environment in their future practice [5][7].

Table 6. Distribution of the students' responses in statements Q33 to Q35 of Section D

\begin{tabular}{|l|c|c|c|c|c|}
\hline \multicolumn{1}{|c|}{ Statement } & $\mathbf{1}$ & $\mathbf{2}$ & $\mathbf{3}$ & $\mathbf{4}$ & $\mathbf{5}$ \\
\hline $\begin{array}{l}\text { Q33. I intend to utilize the WebQuests devel- } \\
\text { oped by my peers at SlideWiki in the future. }\end{array}$ & $\begin{array}{c}10 \\
(8 \%)\end{array}$ & $\begin{array}{c}21 \\
(17 \%)\end{array}$ & $\begin{array}{c}33 \\
(26 \%)\end{array}$ & $\begin{array}{c}46 \\
(37 \%)\end{array}$ & $\begin{array}{c}16 \\
(13 \%)\end{array}$ \\
\hline $\begin{array}{l}\text { Q34. As a future teacher, I would choose to use } \\
\text { SlideWiki for developing OERs. }\end{array}$ & $\begin{array}{c}9 \\
(7 \%)\end{array}$ & $\begin{array}{c}10 \\
(8 \%)\end{array}$ & $\begin{array}{c}32 \\
(26 \%)\end{array}$ & $\begin{array}{c}55 \\
(44 \%)\end{array}$ & $\begin{array}{c}19 \\
(15 \%)\end{array}$ \\
\hline $\begin{array}{l}\text { Q35. As a future teacher, I would choose to } \\
\text { assign my students to use SlideWiki. }\end{array}$ & $\begin{array}{c}11 \\
(9 \%)\end{array}$ & $\begin{array}{c}11 \\
(9 \%)\end{array}$ & $\begin{array}{c}30 \\
(24 \%)\end{array}$ & $\begin{array}{c}54 \\
(43 \%)\end{array}$ & $\begin{array}{c}19 \\
(15 \%)\end{array}$ \\
\hline
\end{tabular}

Table 7. Students' answers to the multiple choice question Q36 and the open-ended question Q37 of Section C

\begin{tabular}{|l|c|}
\hline \multicolumn{2}{|c|}{ Q36. As a future teacher, what type of OERs would you develop in SlideWiki? } \\
\hline \multicolumn{1}{|c|}{ Category selection } & Frequency \\
\hline WebQuests & $99(79 \%)$ \\
\hline Presentations & $84(67 \%)$ \\
\hline Learning Designs & $64(51 \%)$ \\
\hline Q37. As a future teacher, what would you assign your students to do in SlideWiki? \\
\hline Presentations & $82(66 \%)$ \\
\hline WebQuests & $45(36 \%)$ \\
\hline Content authoring group projects & $19(15 \%)$ \\
\hline None & $3(2 \%)$ \\
\hline
\end{tabular}

The OERs that the students -as future teachers- would develop in SlideWiki are presented in Table 7, Q36. It is of no surprise that $79 \%$ of the students would use SlideWiki to develop WebQuests, since they did so when they used the platform for the first time. The fact that $67 \%$ of the students would develop presentations in SlideWiki was also an expected finding due to the structuring of content as Slide Decks. It is quite promising that half of the students would use SlideWiki to develop Learning Designs, since these students declare that they intend to use SlideWiki in another context than the already known ones i.e. WebQuests and presentations. Creating learning designs in SlideWiki could be connected to sharing them with the teacher community and/or developing constructivist learning contexts for their students.

As shown in Table 7, Q37, presentations is the kind of assignment that most students $(66 \%)$ would give as future teachers to their students to carry out in SlideWiki. A somewhat confusing answer is the one given by $36 \%$ of students who said that they would ask their students in the future, to develop WebQuests in SlideWiki. Obviously, that $36 \%$ includes students who misunderstood the question and others who have not got a clear view of what a WebQuest really is. Finally, $15 \%$ of the students would use as future teachers the SlideWiki platform as an online space for their students to organize their projects and work collaboratively in groups. 


\section{Conclusion}

Harnessing the potential of wikis in education has turned out to be very challenging. Empirical studies using wikis as collaborative learning tools yield equivocal findings. This paper reports on a study concerning the SlideWiki platform, focusing on its potential to support collaboration in a teacher education context. Thus, the contribution of the paper is important both in the area of teacher education and as for the development of wikis as crowdsourcing platforms promoting collaborative authoring.

Concerning the students' perceptions of the potential of SlideWiki to serve as an effective tool for collaboratively developing OERs, the study yielded positive results [11]. Most of the students found the platform easy to access and use, appreciated the ability to share their work within their group and access it anytime from anywhere, and felt that being able to author the assignment at their convenience facilitated the collaboration among them. Moreover, the vast majority of students enjoyed collaborating within their group on a shared SlideWiki Deck and considered that this allowed them to save time, collaborate more easily, and contribute more equally to the assigned task. Almost half of the students stated that the collaboration in SlideWiki is more effective than face-to-face collaboration and suggested means, such as a discussion forum, that could further facilitate collaboration. SlideWiki, based on the students' perceptions, seems to have contributed to the enhancement of the sense of community in the class through collaboration. Also, SlideWiki seems to have motivated the students to try harder and improve their work due to its availability to all SlideWiki users and not just to their peers. Moreover, being able to review the fellow groups' OERs while developing their own, stimulated the students' creativity.

The findings concerning the students' actual participation in SlideWiki during the development of their OERs include: a) the unequal distribution of workload among group members, b) the phenomenon of one member dominating the group work, and c) some students insisting to work on their own. The discrepancy between these findings and those of their perceptions of the potential of SlideWiki to support collaboration among co-developers of OERs highlights the need to cultivate the students' collaborative authoring skills. In several cases, especially at the beginning of the course, the students tended to collaborate out of the platform and use just one account to author their OERs. Regarding the timeline of group work, the findings confirm the students' tendency to postpone their work of collaborative content authoring in Wikis just before the deadline of their assignment. On the other hand, we found that the face-to-face lab sessions included in the blended learning structure of the project, triggered the students' collaboration on the platform.

The findings of the study also provide evidence about the SlideWiki's potential to be a useful and effective tool for educators. The students considered that it allows them to easily search for educational resources, locate the ones they need, and reuse them since they are published under the Open Creative Commons license. Furthermore, they believed that the collaboration with peers and the co-authoring of OERs in SlideWiki significantly enhanced their knowledge of learning design. Finally, the students assuming their future role as engineering educators, responded positively to the perspective of integrating SlideWiki in their future practice, in order to develop 
their own OERs, to reuse or repurpose OERs developed by others, or even to assign their students to use it.

\section{AcknowledgEment}

The research "SlideWiki for collaborative learning design" is implemented and funded through the Horizon $2020 \mathrm{EU}$ research and innovation program, SlideWiki EU Project - EU ICT-20-2015 Project SlideWiki, Grant Agreement No 688095.

\section{References}

[1] Dodge, B. (1995). WebQuests: A technique for internet-based learning. Distance educator, 1(2): 10-13

[2] Auer, S., Khalili, A., Tarasowa, D. (2013). Crowd-sourced Open Courseware Authoring with SlideWiki.org. International Journal of Emerging Technologies in Learning (iJET), 8(1): 62-63 https://doi.org/10.3991/ijet.v8i1.2539

[3] Khalili A., Auer S., Tarasowa D., Ermilov I. (2012). SlideWiki: Elicitation and Sharing of Corporate Knowledge Using Presentations. In: ten Teije A. et al. (eds) Knowledge Engineering and Knowledge Management. EKAW 2012. Lecture Notes in Computer Science, vol 7603, Springer, Berlin, Heidelberg. pp. 302-316. https://doi.org/10.1007/978-3-64233876-2 27

[4] Wheeler, S., Yeomans, P., Wheeler, D. (2008). The good, the bad and the wiki: Evaluating student-generated content for collaborative learning. British Journal of Educational Technology, 39(6): 987-995. https://doi.org/10.1111/j.1467-8535.2007.00799.x

[5] LI, Kai Ming (2015). Learning styles and perceptions of student teachers of computersupported collaborative learning strategy using wikis. Australasian Journal of Educational Technology, 31(1): 32-50. https://doi.org/10.14742/ajet.521

[6] O’Bannon, B.W., Lubke, J.K., Britt, V.G. (2013). 'You still need that face-to-face communication': drawing implications from preservice teachers' perceptions of wikis as a collaborative tool. Technology, Pedagogy and Education, 22(2): 135-152. https://doi.org/10. $\underline{1080 / 1475939 X .2012 .755470}$

[7] Judd, T., Kennedy, G., Cropper, S. (2010). Using wikis for collaborative learning: Assessing collaboration through contribution. Australasian Journal of Educational Technology, 26(3): 341-354. https://doi.org/10.14742/ajet.1079

[8] Hadjerrouit, S. (2013). Wiki as a collaborative writing tool in teacher education: Evaluation and suggestions for effective use. Computers in Human Behavior, 32: 301-312. https://doi.org/10.1016/j.chb.2013.07.004

[9] Moundridou, M., Papanikolaou, K. (2017). Educating engineer educators on Technology Enhanced Learning based on TPACK. Proceedings of 2017 IEEE Global Engineering Education Conference (EDUCON), IEEE, pp. 1247-1254. https://doi.org/10. 1109/EDUCON.2017.7943007

[10] Taylor, H.G. (2002). The WebQuest Model for Inquiry-based Learning Using the Resources of the World Wide Web. In: Watson D., Andersen J. (eds) Networking the Learner. WCCE 2001. IFIP - The International Federation for Information Processing, Springer, Boston, MA, Vol. 89, pp.319-328.

[11] Moundridou, M., Zalavra, E., Papanikolaou, K, \& Tripiniotis, A. (2018). Collaborative content authoring: developing WebQuests using SlideWiki. In: Auer, M.E. \& Tsiatsos, T. 
(eds.): The Challenges of the Digital Transformation in Education - Proceedings of the 21st International Conference on Interactive Collaborative Learning (ICL2018) - Vol. 2, Advances in Intelligent Systems and Computing, Springer

[12] Tarasowa, D., Khalili, A., \& Auer, S. (2012). CrowdLearn: Collaborative engineering of (semi-) structured learning objects. Proceedings of the 3rd Russian Conference on Knowledge Engineering and Semantic Web - KESW 2012, Saint-Petersburg, Russia.

[13] Tarasowa, D., Khalili, A., Auer, S. (2015). CrowdLearn: Crowd-sourcing the Creation of Highly-structured E-Learning Content. International Journal of Engineering Pedagogy (iJEP), 5(4): 47-54. https://doi.org/10.3991/ijep.v5i4.4951

[14] Zalavra, E., Papanikolaou, K. (2018). A framework for organising collaborative learning design activities in teacher education. Manuscript submitted for publication.

[15] Salmon, G. (2002). E-tivities: The key to active online learning. London \& New York: Routledge.

[16] Salmon, G. (2013). E-tivities: The key to active online learning. 2nd edition. London \& New York: Routledge.

[17] Kanelopoulos, J., Papanikolaou, K.A., Zalimidis, P. (2017). Flipping The Classroom to Increase Students' Engagement and Interaction in a Mechanical Engineering Course on Machine Design. International Journal of Engineering Pedagogy (iJEP), 7(4): 19-34. https://doi.org/10.3991/ijep.v7i4.7427

[18] Donnelly, D.F, Hume, A. (2015). Using collaborative technology to enhance pre-service teachers' pedagogical content knowledge in Science. Research in Science \& Technological Education, 33(1): 61-87. https://doi.org/10.1080/02635143.2014.977782

[19] Goh, W.W. (2012). Can Wiki Be Used to Facilitate Critical Thinking? : A Qualitative Approach. International Journal of Engineering Pedagogy (iJEP), 2(4): 18-23. https://doi.org/10.3991/ijep.v2i4.2261

[20] Meishar-Tal, H., Gorsky, P. (2010). Wikis: What students do and do not do when writing collaboratively. The Journal of Open and Distance Learning, 25(11): 25-35. https://doi.org/10.1080/02680510903482074

[21] Hadjerrouit, S. (2014). Wiki-mediated Collaborative Writing in Teacher Education - Assessing Three Years of Experiences and Influencing Factors. Proceedings of the 6th International Conference on Computer Supported Education, Vol. 1, pp. 5-14

[22] Keppell, M., Au, E., Ma, A., Chan, C. (2006). Peer learning and learning-oriented assessment in technology-enhanced environments. Assessment \& Evaluation in Higher Education, 31(4): 453-464. https://doi.org/10.1080/02602930600679159

[23] Karasavvidis, I. (2010). Wiki uses in higher education: exploring barriers to successful implementation. Interactive Learning Environments, 18(3): 219-231. https://doi.org/10.1 $\underline{080 / 10494820.2010 .500514}$

\section{$7 \quad$ Authors}

Maria Moundridou is an Assistant Professor of 'Educational Technology \& Multimedia' in the Department of Education at the School of Pedagogical and Technological Education (ASPETE) in Athens, Greece, since 2007. Her research interests span Intelligent Tutoring Systems, Adaptive Hypermedia, User Modelling, \& Virtual Learning Environments. She has participated in a number of national and European $\mathrm{R} \& \mathrm{D}$ projects and published in prestigious journals and conference proceedings in her areas of research. 
Eleni Zalavra is an ICT Teacher at Athens Directorate of Secondary Education. She holds an MSc in Educational Technology from the National University of Athens. Her research interests are in the area of Learning Design and Online Communities.

Kyparisia A. Papanikolaou is an Associate professor of e-learning at the Dpt. of Education, School of Pedagogical and Technological Education, Greece. Her research work has contributed to the design of web-based adaptive learning environments and Technology Enhanced Learning and teacher training. She authored and co-authored more than 100 publications, including journal articles, book chapters and conference papers. She is actively involved in the research community by organizing international workshops in the area of e-learning and ICT in education, serving as conference chair, program committee chair and track chair for several national and international conferences.

Angeliki Trypiniotis is an ICT Teacher at Hellenic Manpower Employment Organization's Training Centres. She holds an MSc in STEM in Education from ASPETE. Her research interests are in the area of E-learning environments.

This article is a revised version of a paper presented at the International Conference on Interactive Collaborative Learning (ICL2018), held September 2018, in Kos, Greece. Article submitted 2018-12-03. Resubmitted 2019-01-25. Final acceptance 2019-01-26. Final version published as submitted by the authors. 